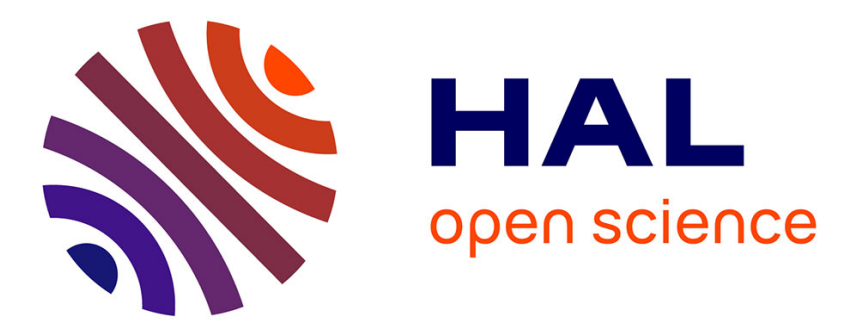

\title{
Experimental and computer simulation studies of dehydration on microporous adsorbent of natural gas used as motor fuel
}

\author{
M.R. Petryk, A. Khimich, M.M. Petryk, J. Fraissard
}

\section{To cite this version:}

M.R. Petryk, A. Khimich, M.M. Petryk, J. Fraissard. Experimental and computer simulation studies of dehydration on microporous adsorbent of natural gas used as motor fuel. Fuel, 2019, 239, pp.13241330. 10.1016/j.fuel.2018.10.134 . hal-02273125

\section{HAL Id: hal-02273125 \\ https://hal.sorbonne-universite.fr/hal-02273125}

Submitted on 28 Aug 2019

HAL is a multi-disciplinary open access archive for the deposit and dissemination of scientific research documents, whether they are published or not. The documents may come from teaching and research institutions in France or abroad, or from public or private research centers.
L'archive ouverte pluridisciplinaire HAL, est destinée au dépôt et à la diffusion de documents scientifiques de niveau recherche, publiés ou non, émanant des établissements d'enseignement et de recherche français ou étrangers, des laboratoires publics ou privés. 


\title{
Experimental and Computer simulation studies of dehydration on microporous adsorbent of natural gas used as motor fuel.
}

\author{
M.R. Petryk ${ }^{\mathrm{a} 1}$, A. Khimich ${ }^{\mathrm{b}}$, M.M. Petryk ${ }^{\mathrm{a} 2}$, J. Fraissard $^{\mathrm{c} *}$ \\ ${ }^{a}$ Modélisation du Transfert de Masse, Ternopil Ivan Puluj National Technical University, Ukraine \\ ${ }^{a l}$ Mykhaylo_Petryk@tu.edu.te.ua ; ${ }^{2}$ mashapetryk@gmail.com \\ ${ }^{b}$ Glushkov Institute of Cybernetics of NAS of Ukraine, 40 Glushkova av., 03187 Kyiv, Ukraine \\ khimich505@gmail.com \\ $c^{*}$ Sorbonne Universités, UPMC, ESPCI-LPEM, 10 rue Vauquelin, F-75231 Paris, France \\ jacques.fraissard@upmc.fr Tel.:33609877865
}

\begin{abstract}
An experimental and theoretical study of the dehydration of natural gas using microporous silica beds for motor fuel technology in extreme winter climates is described. Analytical solutions to the problem of non-isothermal adsorption and desorption are based on Heaviside's operational method and Laplace integral transform, but the development of calculations is quite original. Experimental and modeling distributions of moisture and temperatures of gas at the inlet and outlet of the silica beds for each adsorption - desorption phase at different times are presented. The distribution of moisture within the beds for the full dehydration - regeneration cycle is determined.
\end{abstract}

\section{Keywords}

Natural gas dehydration, diffusion of adsorbed gas; adsorption and desorption of gases; modelling; Heaviside's operational method; Laplace integral transform.

\section{Introduction}

The main anthropogenic sources of atmospheric pollutants are the processes by which energy is generated for transport and industry. It has been demonstrated that the transport sector is the emission source that contributes the most to global warming at present, and it will probably remain so in the immediate future [1].

Natural gas is an important source of primary energy. Its use as a motor fuel for transport and other sectors of industry saves liquid petroleum products, significantly improves the atmosphere of cities and slows the process of global warming. However, the reliability of the exploitation of process equipments, including motors of vehicles that run on natural gas, is largely dependent on the quality of gas used as fuel. This must be in accordance with European Union specifications governing the security and safety of such technical equipment's [2].

Under normal production conditions, natural gas contains water vapor. Therefore, for the reliable exploitation of vehicles in winter at temperatures down to $-30{ }^{\circ} \mathrm{C}$ it is accepted that the humidity content of the gas must not exceed $0.009 \mathrm{~g} / \mathrm{m}^{3}$, corresponding to a dew point of $-60{ }^{\circ} \mathrm{C}$ under normal conditions [3].

Extensive literature is available on common gas dehydration systems including solid and liquid desiccant and refrigeration-based systems [4,5,6,7]. Netusil and Pavel [8] have compared the different methods for natural gas dehydration that are widely applied in industry, according to their energy requirements and suitability for use. They concluded that adsorption is preferred when a very low $T_{d e w}$ of natural gas is required. Currently, adsorption-based processes rely on a technology which uses high temperatures for the regeneration of the adsorbent $[3,9,10]$. For example, molecular 
sieves require large amounts of energy to heat them to the regeneration temperature (over $350{ }^{\circ} \mathrm{C}$ ), and then to cool them to the adsorption temperature $\left(\leq 25^{\circ} \mathrm{C}\right)$, increasing the cost of gas used as motor fuel. Lower operating costs for drying gas are possible with short adsorption-desorption cycles and low-temperature regeneration of the adsorbent. In our plant, a microporous silica gel is used because of its ability to provide extremely low dew points. But the main purpose of this study is not to confirm the effectiveness of the adsorption-desorption technology for the dehydration of natural gas and to show that our installation is very efficient. For the first time, it has been possible to specify all the processes along the columns during non-isothermal adsorption and desorption. For the modeling we have used the Heaviside operational method and the Laplace transform, but the development of calculations is quite original.

\section{Experimental system for gas dehydration and adsorbent regeneration}

The scheme of the plant is presented in Figure 1. The two columns have the dimensions: height: $1.65 \mathrm{~m}$, diameter: $0.8 \mathrm{~m}$. They are filled with microporous silica gel KSMH (Ukraine) with the following characteristics: - density: $720 \mathrm{~g} / \mathrm{dm}^{3}$; - specific surface area: $450-600 \mathrm{~m}^{2} / \mathrm{g}$; pore diameter: $5^{*} 10^{-9}-8^{*} 10^{-9} \mathrm{~m}$; pore volume: $0.6-0.8 \mathrm{ml} / \mathrm{g}$; radius of solid particles: $1.4-3 \mathrm{~mm}$.

The natural gas to be dehydrated is at a temperature of $10-12^{\circ} \mathrm{C}$ and a pressure of $25 \mathrm{MPa}$; it cools the column (for example A1 in the figure) at the same time as water is adsorbed. On leaving A1 the water concentration of the gas should not be greater than $0.009 \mathrm{~g} / \mathrm{m}^{3}$.

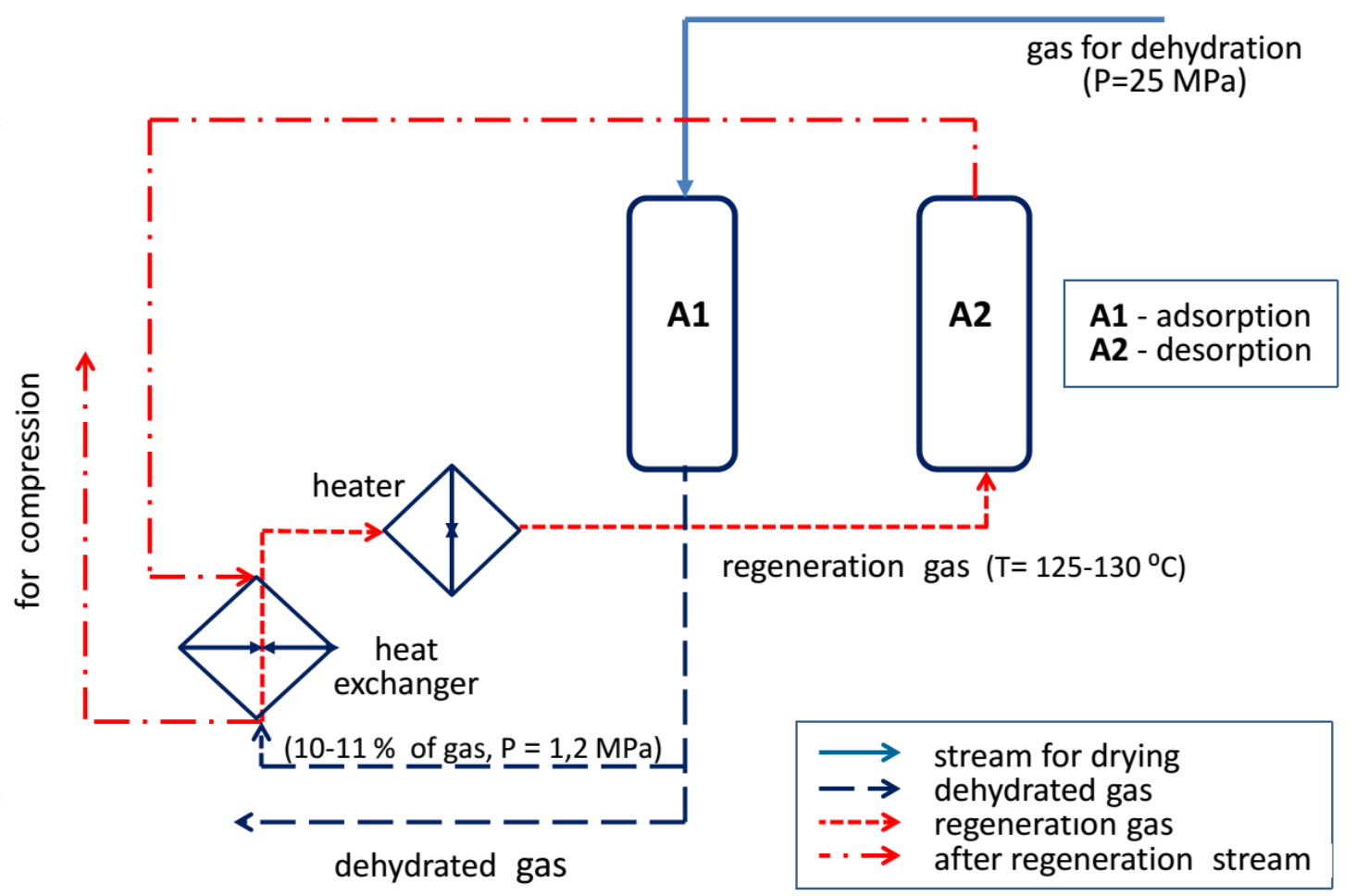

Figure 1. Schema of experimental plant with water adsorption in A1 and regeneration in A2.

Part of the dehydrated gas is heated in the counter-flow heat exchanger and sent to regenerate the adsorbent (A2 in the figure) at a pressure of 1.0-1.2 $\mathrm{MPa}$ and temperature of $125-130{ }^{\circ} \mathrm{C}$. It thus warms the second column and eliminates the desorbed water. The two columns of silica (A1, A2) are alternately in the "dehydration" or "regeneration" mode. The experimental conditions of the system are summarized in Table 1. The study was carried out during four-hour cycles of dehydration and regeneration. 
Table 1 : Experimental conditions

\begin{tabular}{|l|l|}
\hline Environment temperature, ${ }^{\circ} \mathrm{C}$ & -5 to +3 \\
\hline Gas entering for dehydration: & 1600 \\
- - Consumption, $\mathrm{m}^{3} / \mathrm{h}$ & 25.0 \\
- Pressure, $\mathrm{MPa}$ & $10-12$ \\
- - Temperature, ${ }^{\circ} \mathrm{C}$ & $0.16-0.18$ \\
- Moisture content, $\mathrm{g} / \mathrm{m}^{3}$ & \\
\hline & \\
\hline Regeneration of the adsorbent: & $155-160$ \\
- Consumption $(10-11 \%$ of gas consumption for drying $), \mathrm{m}^{3} / \mathrm{h}$ & $1.0-1.2$ \\
- Pressure, $\mathrm{MPa}$ & $125-130$ \\
- Temperature, ${ }^{\circ} \mathrm{C}$ & $0.00035-0.0017$ \\
- Moisture content, $\mathrm{g} / \mathrm{m}^{3}$ & \\
\hline
\end{tabular}

\section{Mathematical model of non-isothermic adsorption and desorption in microporous solids}

The modeling of the kinetics of gas dehydration processes on a microporous adsorbent and the corresponding regeneration is based on our approach [11] using a mathematical model that includes mass balance and heat in ref. 12 and 13. The meaning of the terms is given in the Nomenclature.

$$
\begin{aligned}
& \frac{\partial c(t, z)}{\partial t}+\frac{\partial a(t, z)}{\partial t}+u \frac{\partial c}{\partial z}=D_{\text {int } e r} \frac{\partial^{2} c}{\partial z^{2}} \\
& -H \frac{\partial T(t, z)}{\partial t}-u h_{g} \frac{\partial T}{\partial z}-Q_{a d s} \frac{\partial a}{\partial t}-X^{2} T+\Lambda \frac{\partial^{2} T}{\partial z^{2}}=0, \\
& \frac{\partial a}{\partial t}=\beta(c-K a(z, t)),
\end{aligned}
$$

Initial conditions:

a) adsorption: $\quad$ b) desorption:

$$
\begin{aligned}
\left.c(t, z)\right|_{t=o}=0, & \left.c(t, z)\right|_{t=o}=c_{0}, \\
\left.T(t, z)\right|_{t=o} & =T_{0},
\end{aligned}
$$

Boundary conditions:

$$
\begin{array}{ll}
\text { a) adsorption: } & \text { b) desorption: } \\
\left.c(t, z)\right|_{z=0}=c_{i n}, & \left.c(t, z)\right|_{z=0}=c_{i n}(t), \\
\left.\frac{\partial}{\partial z} c(t, z)\right|_{z=\infty}=0, & \left.\frac{\partial}{\partial z} c(t, z)\right|_{z=\infty}=0, \\
& \left.T(t, z)\right|_{z=0}=T_{i n}(t),\left.\frac{\partial}{\partial z} T(t, z)\right|_{z=\infty}=0 .
\end{array}
$$

During adsorption $C_{i n}$ is roughly constant for $\mathrm{z}=0$ (top of the columns). We use the same symbol $\mathrm{C}_{0}$ for adsorption and desorption because the calculation methodology is the same for both. 
For the model we choose columns of unlimited height, since it is not known in advance what the concentration of moisture in the gas at the exit of the column of regeneration will be. However, if an infinite length is assumed, the concentration will decrease from the beginning to the end, where it will be equal to 0 . If we apply this condition for a limited height of the columns at the end of which the gas leaves, the calculation will not be completely correct.

The solution of the system (1)-(7) was obtained using Heaviside's operational method and is presented in the Appendix [13, 14, 15].

Let us point out that for a first approach to this problem, given the complexity of the calculations, the authors have used some simplifications; for example, the co-adsorption of methane is neglected; the Henry's law constant $(K)$ was calculated for the temperature $\mathrm{T}=40 \mathrm{C}$ according to the reference [16] and supposed to be constant $K=300$; the isosteric heat of adsorption for the water isotherm was also assumed to be constant $Q_{\mathrm{ads}}=2200 \mathrm{~kJ} / \mathrm{kg}[16,17]$. The total mass transfer coefficient $\beta=$ 0.85-0.95 s-1. was calculated as the inverse of the total resistance in the system, which includes mainly the external and internal mass transfer resistance [18]:

$$
\frac{1}{\beta}=\frac{1}{\beta_{\text {inter }}}+\frac{1}{\beta_{\text {iintra }}}
$$

\section{Analysis of experiment and simulation}

Moisture concentrations of the gas that enters the drying adsorbent column (adsorption phase) during a dehydration cycle are presented in Figure 2. These variations are due to the minor fluctuations of the gas pressure in the network. The corresponding average moisture at the inlet, $0.175 \mathrm{~g} / \mathrm{m}^{3}$, is used for the simulations.

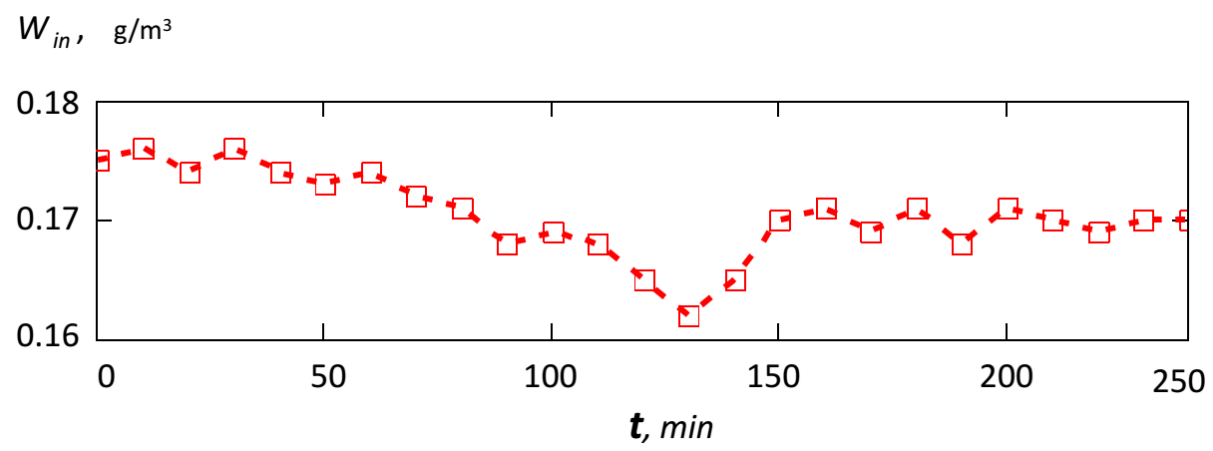

Figure 2. Experimental concentration of gas moisture at the inlet of the adsorbent column during the adsorption phase

Figure 3 displays the moisture variations against time of dehydrated gas at the outlet of the adsorbent column. The average concentration (used for simulation) does not exceed $0.003 \mathrm{~g} / \mathrm{m}^{3}$, which correspond to the technical requirements of the quality of gas for its further use as a motor fuel [10].

Adsorbent regeneration (desorption phase) is carried out with a small fraction of the dehydrated gas $\left(10 \%\right.$ in our experiments) heated at $125-130{ }^{\circ} \mathrm{C}$. Figure 4 shows the variation of the temperature near the inlet $T_{\text {in }}\left(T_{1}, T_{2}\right)$ and outlet $T_{\text {out }}\left(T_{3}, T_{4}\right)$ of the column during the desorption phase. 


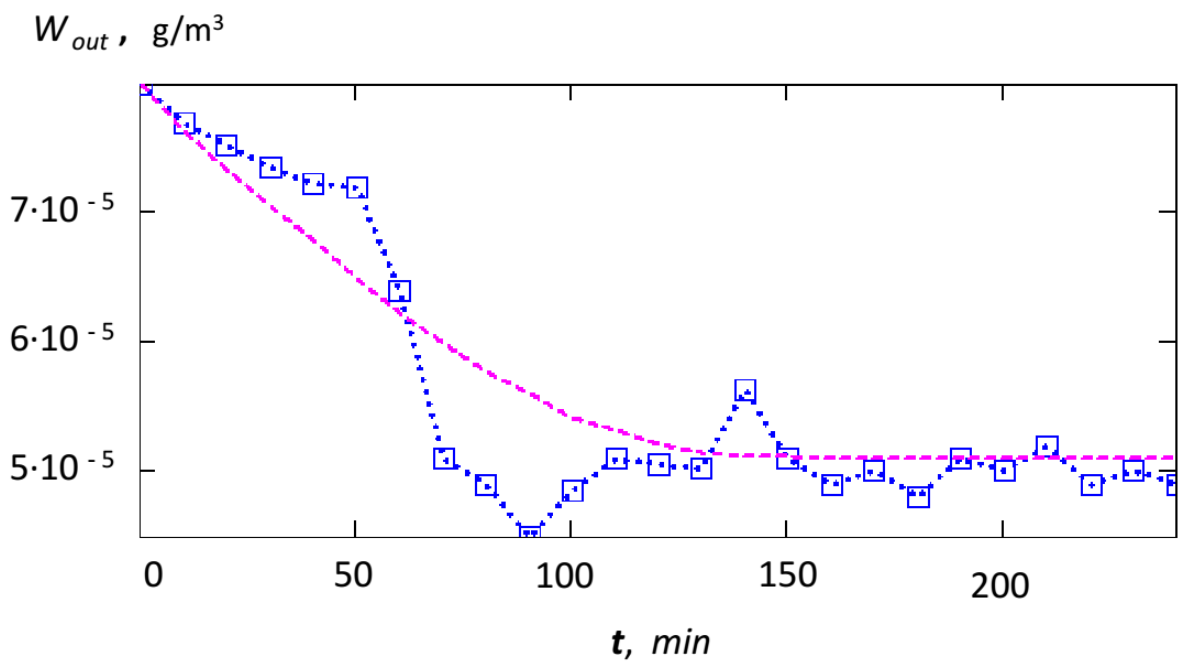

Figure 3. Moisture content of dehydrated gas at the outlet of the adsorbent column. ( blue square points - experiment; dotted red line - model).

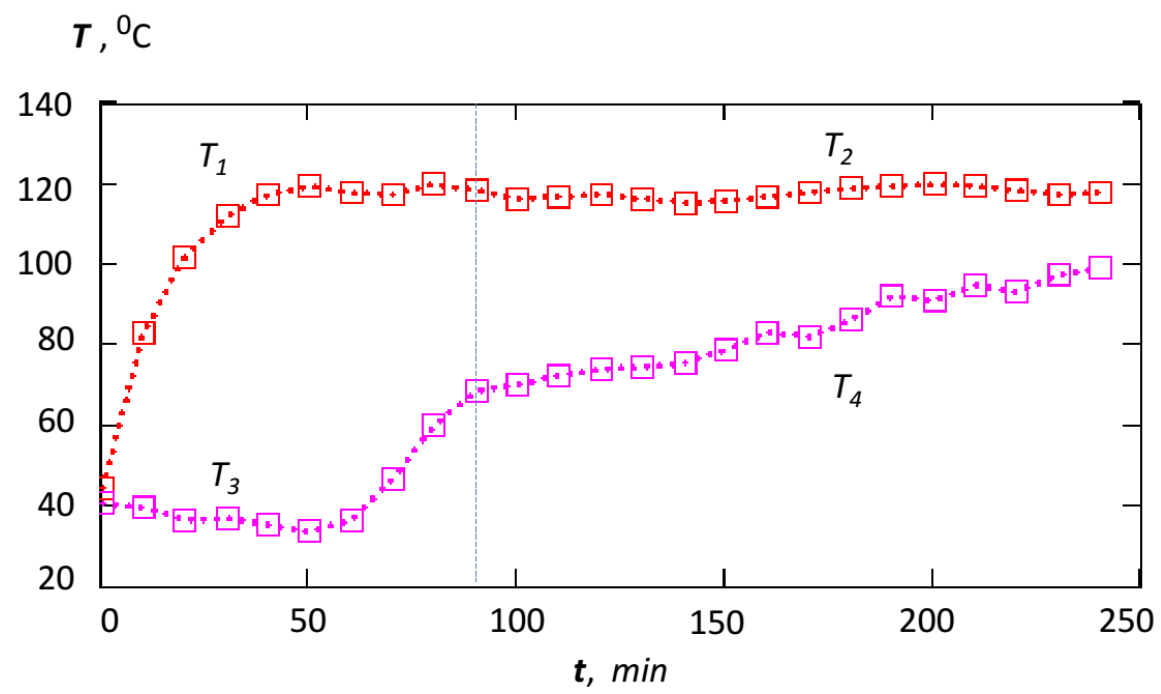

Figure 4. The temperature of gas near the inlet $T_{\text {in }}\left(T_{1}, T_{2}\right)$ and at the outlet $T_{\text {out }}\left(T_{3}, T_{4}\right)$ of the column of regeneration (squares - experiment, dotted line - model) .

$$
w_{r e g}, \mathrm{~g} / \mathrm{m}^{3}
$$

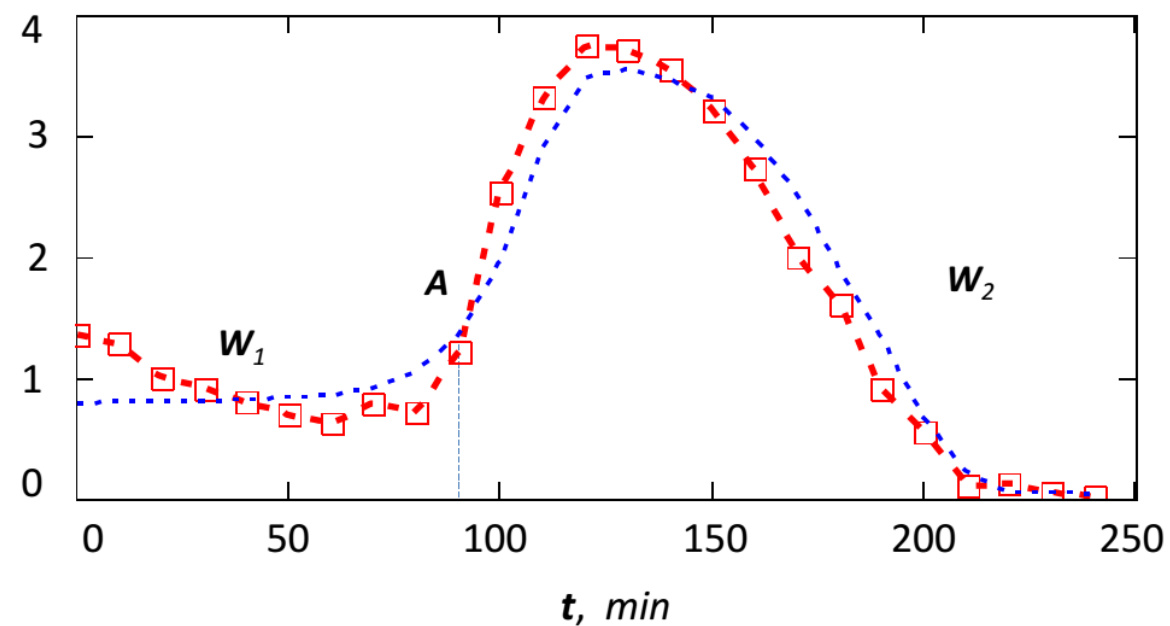

Figure 5. Moisture of the gas at the outlet of the column during the regeneration of the adsorbent during 240 minutes (square red points - experiment, dotted blue line - model) 
The variation of the moisture of the gas at the outlet of the column of regeneration (Fig. 5) shows the kinetics of the internal desorption of the moisture during 240 minutes.

Figure 4 and 5 show that the regeneration process is characterized by two specific periods: the heating of the adsorbent, corresponding roughly to the first 90 minutes (Fig. 4, curves $T_{1}$ and $T_{3}$, Fig. 5, curve $\mathbf{w}_{1}$ ) and the regeneration period (Fig. 4, curves $T_{2}$ and $T_{4}$, Fig. 5, curve $\mathbf{w}_{2}$ ). At the beginning of the regeneration, during bed heating, desorption of water is low (moisture content of the regenerated gas is $0.5-0.9 \mathrm{~g} / \mathrm{m}^{3}$ ), and the average temperature of the gas at the outlet of the column reaches $30-50{ }^{\circ} \mathrm{C}$. Further there is a higher and stable temperature $T_{\text {in }} \approx 120-125{ }^{\circ} \mathrm{C}$ and $T_{\text {out }}$ increases continuously. After about 90 minutes there is a sharp increase in the desorption with a maximum around 120 minutes (Fig. 5 , point $A=3.75 \mathrm{~g} / \mathrm{m}^{3}$ ) due to the elimination of the water very slightly physisorbed on the adsorbent. Then the average moisture concentration of the gas decreases sharply and is $0.50-0.2 \mathrm{~g} / \mathrm{m}^{3}$ after about 200 minutes. At the end of the regeneration cycle (240 minutes) this concentration is negligible (less than $0.005 \mathrm{~g} / \mathrm{m}^{3}$ ).

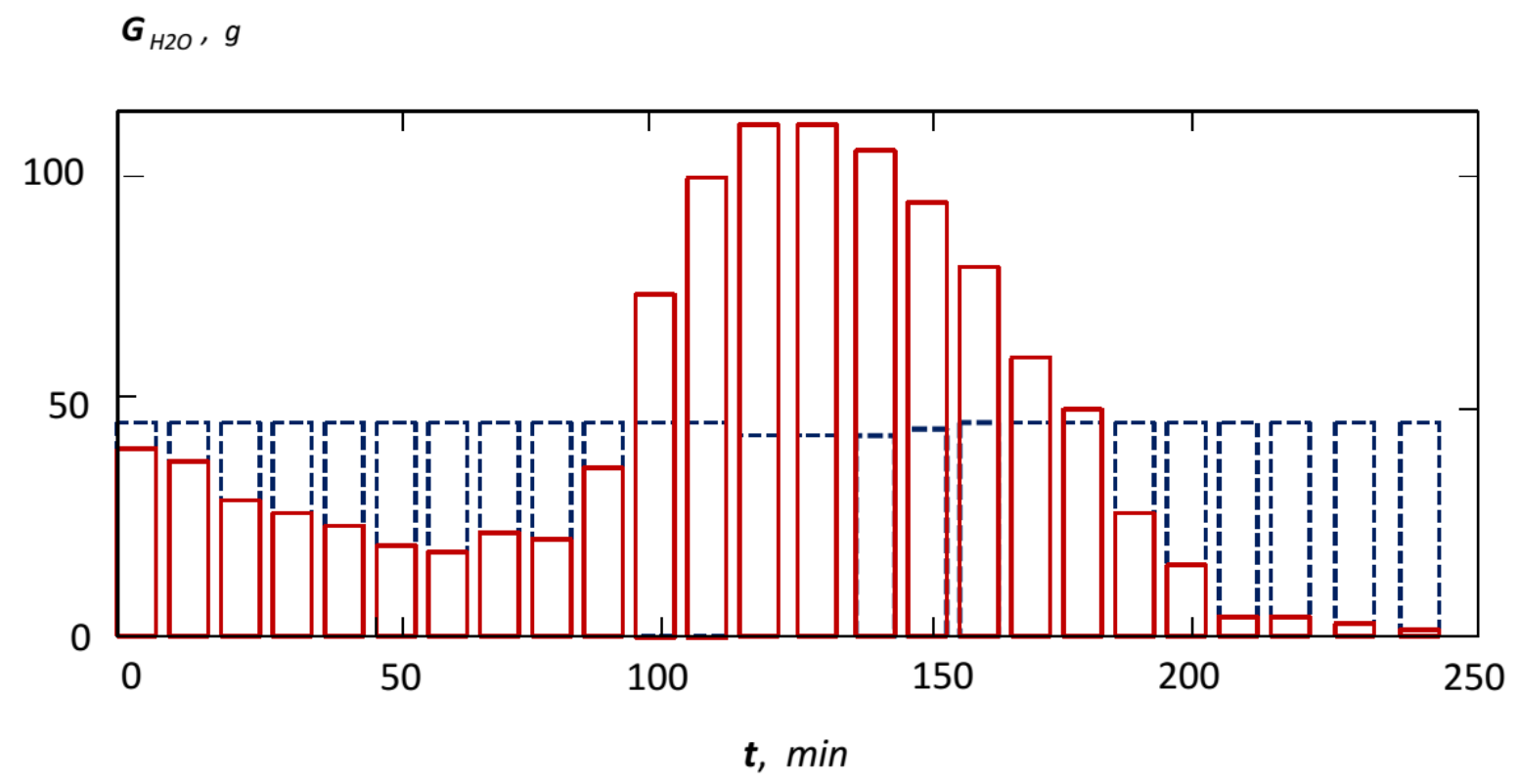

Figure 6. Variation of the amount of adsorbed and desorbed water during the four-hour cycle (red diagram - regeneration, blue - drying)

Figure 6 shows the amount of adsorbed and desorbed water during the four-hour "dryingregeneration" cycle. During this time, $1089 \mathrm{~g}$ of water are adsorbed and $1067 \mathrm{~g}$ are eliminated, so $22 \mathrm{~g}$ of moisture are still left in the adsorbent, i.e. about $2 \%$ of adsorbed moisture. This very small difference could correspond either to experimental errors or to the formation of few stable $\mathrm{OH}$ groups at the highest temperature.

Figure 7 shows the adsorption isotherms for the entire water concentration range in the column calculated using the Langmuir equation of the adsorption equilibrium [16, 19]:

$$
\frac{a}{a_{\text {full }}}=\frac{k_{0}^{\prime} \exp \left(-\frac{\Delta H_{a d s}}{R T}\right) p}{1+k_{0}^{\prime} \exp \left(-\frac{\Delta H_{a d s}}{R T}\right) p} .
$$


Here $\Delta H_{a d s}=Q_{\text {ads }} / \mu$ - energy of activation, $\mathrm{kJ} /$ mole; $R$ - gas constant, $\mathrm{kJ} /($ mole. $\mathrm{K}) ; \quad a_{\text {full }}$ - the concentration (amount) of adsorbate at saturation of the micropores and intercrystallite space of the adsorbent, $\mathrm{kg} / \mathrm{kg} ; p$ - pressure; $k_{0}^{\prime}$ - the equilibrium constant.

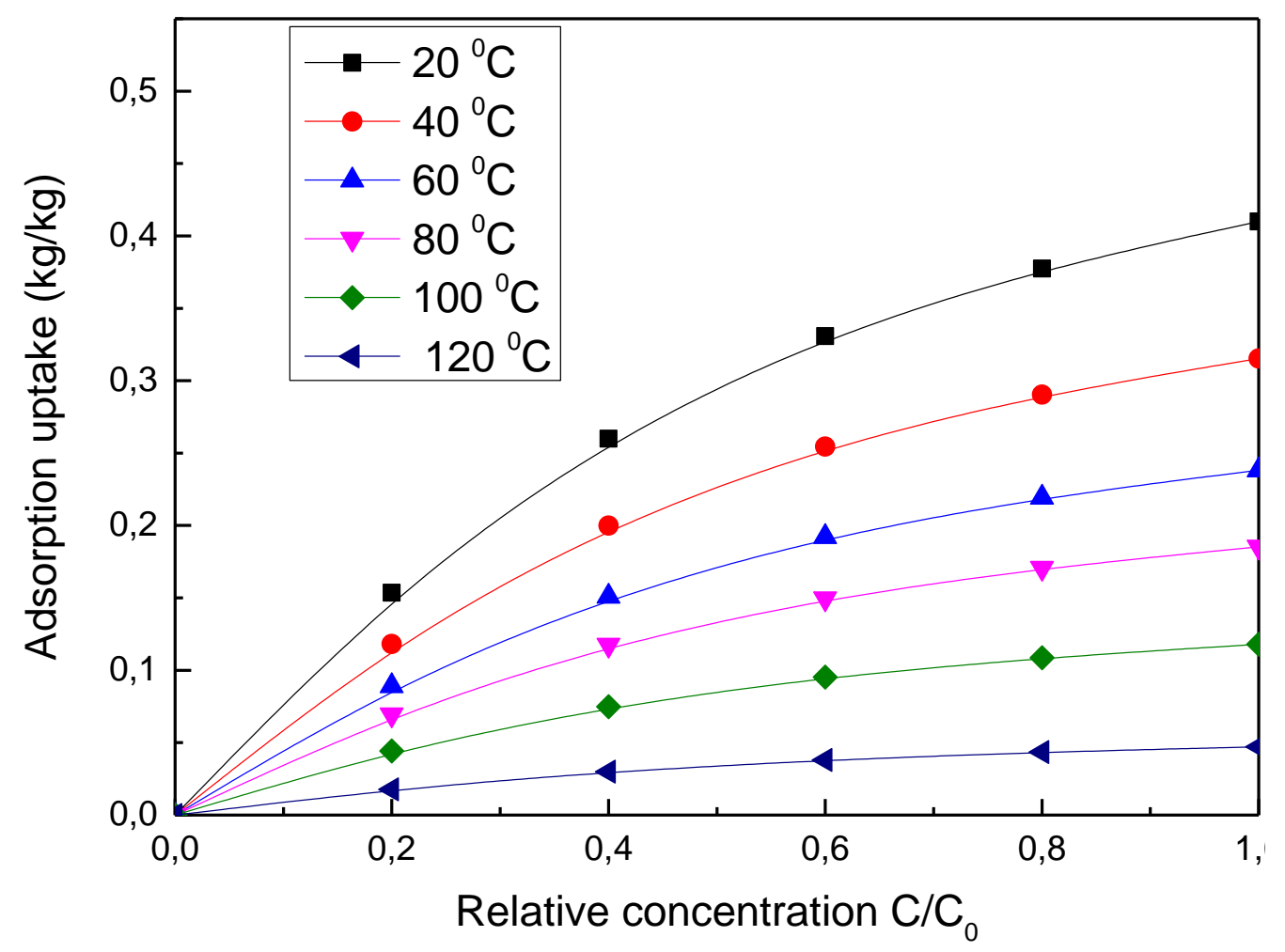

Figure 7. The isotherms for the entire range of moisture concentration in the column.

Remarks on the approximations:

- The Henry law constant $K$ is assumed independent of $T$ and $p$. In a more precise study we will try to take into account the variarion of $K$ with the pressure using for example the data of Do [16] and Karger et al [20] for the adsorption of water on silica, in a form of the type $K=k_{0} \cdot p$ which will take into account the influence of pressure differently for adsorption $(p=25 \mathrm{MPa})$ and desorption $(p=1.2 \mathrm{MPa})$, where $k_{0}=k_{0}^{\prime} \exp \left(-\frac{\Delta H_{a d s}}{R T}\right)=\frac{1}{p} \frac{a / a_{\text {full }}}{\left(1-\frac{a}{a_{\text {full }}}\right)}$.

-In this model, the pressure drop in the column is not taken into account. The next model will be improved by the pressure change equation.

-The isosteric heat of adsorption for the water isotherm is assumed constant. In the proposed new nonlinear model, the temperature dependence will be implemented directly in the Langmuir nonlinear adsorption equilibrium, which should improve the simulation results.

-The influence of the adsorption of methane is not taken into account. It is certain that there must be some amount of methane adsorbed at this high pressure. The literature data, mainly on the adsorption of $\mathrm{CH}_{4}$ on activated carbon (energy storage problem), all show that the presence of water partially inhibits the adsorption of methane, even at high $\mathrm{CH}_{4}$ pressures; only in the case of very humid systems can there be formation of methane hydrates at very high pressure $[21,22]$. This is 
why the lack of experimental data on our installation made any simulation impossible. The problem is all the more complex as the adsorption of the methane should be dependent on the corresponding concentration of adsorbed water at each point of the column and at each instant.

The small difference between the theoretical and experimental results could be due to the fact that the experimental data take into account the whole environment, and therefore the presence of adsorbed methane, which is not the case of simulation. This could mean that the concentration of adsorbed methane is low.

\section{Conclusion}

Our experimental and theoretical studies have confirmed the effectiveness of the "adsorptiondesorption" technology for the dehydration of natural gas used as fuel in extreme winter climates. After each drying cycle, the residual moisture content of the gas is lower than the maximum allowable value of $0.009 \mathrm{~g} / \mathrm{m} 3$. But this was not the main purpose of our study. The solution of the proposed mathematical model for the gas drying process using the adsorption of water on porous solid and its regeneration is based on an original algorithm using the Heaviside operational method and the Laplace transform. The development of calculations is quite original. The result allows instantaneous knowledge along the columns, during the non-isothermal adsorption and desorption, of: - the moisture of the gas phase; -the water concentration of the adsorbed phase; - the temperature of the gas stream. This original mathematical treatment can serve as a model for many applications relating to this type of process, such as for example the purification of confined atmospheres.

\section{Nomenclature}

$c$ - concentration of moisture of the gas phase in the column;

$a$ - concentration of moisture adsorbed in the solid phase;

$T$ - temperature of gas phase flow, ${ }^{\circ} \mathrm{C}$;

$u$ - velocity of gas phase flow, $\mathrm{m} / \mathrm{s}^{2}$;

$D_{\text {inter }}$ - effective longitudinal diffusion coefficient;

$\Lambda$ - coefficient of thermal diffusion along the columns;

$h_{g}$ - gas heat capacity;

$Q_{a d s}$ - heat of adsorption, $\mathrm{kJ} / \mathrm{kg}$;

$\mu-$ molecular mass of adsorbat, $\mathrm{kg} / \mathrm{mole}$;

$H$ - total heat capacity of the adsorbent and gas;

$\varphi(t, z)$ - function of adsorption equilibrium $(\varphi(t, z) \approx \gamma a(t, z))$;

$\mathrm{X}^{2}=2 \alpha_{n} / R$ - coefficient of heat loss through the wall of the adsorbent;

$\mathrm{R}$ - radius of solid particles of the adsorbent, $\mathrm{m}$;

$\alpha_{h}$ - heat transfer coefficient;

$K$ - Henry's constant;

$\beta$ - total mass transfert coefficient, $\mathrm{s}^{-1}$;

$\beta_{\text {inter }}-$ coefficient of inter mass transfer, $\mathrm{s}^{-1}$;

$\beta_{\text {intra }}$ - coefficient of intra mass transfer, $\mathrm{s}^{-1}$;

$z$ - distance from the top of the bed for mathematical simulation, $\mathrm{m}$;

$\mathrm{Z}-$ dimensionless coordinate $=$ abscissa $\mathrm{z} /$ height of the column .

in - index of parameter names (concentration, temperature) in the inlet of the column.

\section{Acknowledgements}

This work was supported by the Ternopil Ivan Puluj National Technical University and the Academy of Sciences of Ukraine. 


\section{References}

[1] Unger N., Bond T.C., Wang J.S., Koch D.M., Menon S., Shindell D.T., Bauer S. Attribution of climate forcing to economic sectors, Proc. Natl. Acad. Sci., 2010, 107(8), 3382-7.

[2] Euro 5 and Euro 6 standards: reduction of pollutant emissions from light vehicles. Available at: europa.eu/legislation_summaries/environment/air_pollution/128186_es.htm (2010, May 5).

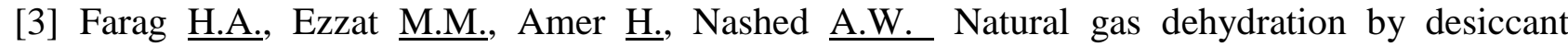
materials. Alexandria Engineering Journal. Vol., 2011, 50 (4), 431-9

[4] Gandhidasan P., Al-Farayedhi AA, Al-Mubarak AA. Dehydration of natural gas using solid desiccants. Energy 2001, 26, 855-68.

[5] Karimi A., Abdi MA. Selective dehydration of high-pressure natural gas using supersonic nozzles. Chemical Engineering and Processing 2009,48, 560-8.

[6] Gas Processors Suppliers Association. GPSA engineering data book. 12th ed. Tulsa, OK: Gas Processors Suppliers Association; 2004. Section 16, 1-13.

[7] Bahadori A., Mokhatab S. Simple correlation accurately predicts densities of glycol solutions. Petroleum Science and Technology 2009, 27, 325-30.

[8] Netusil M., Pavel D. Comparison of three methods for natural gas dehydration. Journal of Natural Gas Chemistry. 2011, 20(5), 471-76.

[9] Puertolas B., Navarro M.V., Lopez J.M., Murillo R., Mastral A.M., Garcia T. Modelling the heat and mass transfers of propane onto a ZSM-5 zeolite. Separation and Purification Technology. 2012, 86,127-36.

[10] Petryk M., Parafeinyk V., Kruchnevytch T., Zeria A. The gas dehydration block of NGV filling stations BCV 250. Chemical Technology. Naukova Dumka. 1988, 6, 59-61.

[11] Sergienko I., Petryk M., Khimith O.N., Mykhalyk D., Leclerc S., Fraissard J. Mathematical Modelling of Diffusion Process in Microporous Media (Numerical analysis and application). National Academy of Sciences of Ukraine. Kyiv, 2014, 196 p.

[12] Zolotarev P. Some theoretical models of the kinetics of sorption and desorption, and their relationship. Sorption and chromatographic processes. 2010, 10(6), 853-63.

[13] Petryk M. Mathematical Modeling of Nonlinear Non-isothermic Process of Diffusion and Adsorption in Compressed Layer of Adsorbent. Integral Transformations and Application in Boundary Problems. Bulletin of Institute of Mathematics. National Academy of Sciences of

O. Ukraine. Kyiv, 1994, 6, 151-64.

[14] Heaviside Electromagnetic Theory. The Electrician. Vo1. 1-3. London, E.C. 1893.

[15] Lavrentiev M.A., Shabat B.V. Methods of theory of functions of a complex variable. M. Nauka, 1973, 736 p.

[16] Do, D.D. Adsorption Analysis: Equilibria and Kinetics, Imperial College Press, Singapore, 1998.

[17] Keltsev N.V. The fundamentals of the adsorption technique [in Russian]. M. Khimiya, 1984, $592 \mathrm{p}$.

[18] Aérov M. E.and Todes O. M. Hydraulic and Thermal Principles of the Operation of Installations Incorporating Stationary and Fluidized Granular Beds [in Russian].M. Khimiya, 1968.

[19] Ruthven D.M. Principles of Adsorption and Adsorption Processes, John Wiley, New York, 1984. $433 \mathrm{p}$

[20] Kärger J.,Ruthven D., Theodorou D. Diffusion in Nanoporous Materials. Hoboken, John Wiley \& Sons, 2012, 660 p. 
[21] Zhou, L., Ming, L., Effect of moisture in microporous activated carbon on the adsorption of methane, Carbon, 2001, 39, 771-785.

[22] Krooss, B.M., van Bergen, F, High-pressure methane and carbon dioxide adsorption on dry and moisture-equilibrated Pennsylvanian coals, International Journal of Coal Geology,2002, 51, 69-92

[23] Petryk M., Vorobiev E. Liquid Flowing from Porous particles During the Pressing of Biological Materials. Computer \& Chem. Eng., 2007, 31, 1336-1345.

\section{Appendix}

\section{Methodology of analytical solutions of the adsorption-desorption model}

The mathematical model of adsorption and desorption cycle of drying gas process and adsorbent regeneration, including mass balance and temperature $[11,13]$ is given by:

$$
\begin{aligned}
& \frac{\partial c(t, z)}{\partial t}+\frac{\partial a(t, z)}{\partial t}+u \frac{\partial c}{\partial z}=D_{\text {int } e r} \frac{\partial^{2} c}{\partial z^{2}} \\
& -H \frac{\partial T(t, z)}{\partial t}-u h_{g} \frac{\partial T}{\partial z}-Q_{a d s} \frac{\partial a}{\partial t}-\mathrm{X}^{2} T+\Lambda \frac{\partial^{2} T}{\partial z^{2}}=0 \\
& \frac{\partial a}{\partial t}=\beta(c-K a(z, t))
\end{aligned}
$$

Initial conditions:

$$
\begin{array}{cc}
\text { a) adsorption: } & \text { b) desorption: } \\
\left.c(t, z)\right|_{t=o}=0, & \left.c(t, z)\right|_{t=o}=c_{0}, \\
& \left.T(t, z)\right|_{t=o}=T_{0},
\end{array}
$$

Boundary conditions:

a) adsorption:

b) desorption:

$$
\begin{array}{ll}
\left.c(t, z)\right|_{z=o}=c_{i n}, & \left.c(t, z)\right|_{z=0}=c_{i n}(t), \\
\left.\frac{\partial}{\partial z} c(t, z)\right|_{z=\infty}=0, & \left.\frac{\partial}{\partial z} c(t, z)\right|_{z=\infty}=0, \\
& \left.T(t, z)\right|_{z=0}=T_{i n}(\mathrm{t}),\left.\frac{\partial}{\partial z} T(t, z)\right|_{z=\infty}=0 .
\end{array}
$$

We use the same symbol $\mathrm{c}_{0}$ for the adsorption and desorption because the methodology of calculation is the same for both.

First of all we obtain the analytical solution of the eq. (A.1)-(A.6), assuming conditions $\left.c(t, z)\right|_{z=0}=c_{i n} \equiv$ const (adsorption). At the end we generalize this solution to the conditions $\left.c(t, z)\right|_{z=0}=c_{i n}(t)$ (desorption).

To find the analytical solution of the problem (A.1)-(A.6) where the functions $c$ and $\mathrm{T}$ depend on the concentration, the time and coordinate $z$, we use Heaviside's operational method [14,15]. Solutions $c$ and $T$ are obtained according to the following procedure:

a) first the Laplace transforms of the functions $c$ and $T$ are determined: 


$$
\begin{aligned}
& c^{*}(p, z)=\int_{0}^{\infty} c(t, z) \mathrm{e}^{-p t} d t \equiv L[c], a^{*}(p, Z)=\int_{0}^{\infty} a(t, z) \mathrm{e}^{-p t} d t \equiv L[a], \\
& T^{*}(p, z)=\int_{0}^{\infty} T(t, z) \mathrm{e}^{-p t} d t \equiv L[T],
\end{aligned}
$$

where $p$ is a complex-value parameter of the Laplace transformation.

b) then the solutions, $c$ and $T$, are obtained by using the Laplace inverse transform of the functions $c^{*}$ and $T^{*}$ with respect to the variable $p$.

Applying the Laplace transformation to eq. (A.1)-(A.6) one obtains:

$$
\begin{aligned}
& p c^{*}(p, z)-c_{0}+p a^{*}(p, z)+u \frac{d}{d z} c^{*}=D_{\text {inter }} \frac{d^{2}}{d z^{2}} c^{*}, \\
& -H\left(p T^{*}(p, z)-T_{0}\right)-u h_{g} \frac{\partial}{\partial z} T^{*}-Q_{a d s} p a^{*}-\mathrm{X}^{2} T^{*}+\Lambda \frac{d^{2} T}{d z^{2}} T^{*}=0, \\
& a^{*}=\frac{\beta}{p+\beta K} c^{*}
\end{aligned}
$$

Boundary conditions:

a) adsorption:

$$
\begin{aligned}
& \left.c^{*}(p, z)\right|_{z=o}=\frac{1}{p} c_{i n}, \\
& \left.\frac{\partial}{\partial z} c^{*}(p, z)\right|_{z=\infty}=0,
\end{aligned}
$$

b) desorption:

$$
\begin{aligned}
\left.\frac{d}{d z} c^{*}(p, z)\right|_{z=\infty} & =0, \\
\left.c^{*}(p, z)\right|_{z=o} & =\frac{1}{p} c_{i n}, \\
\left.\frac{\partial}{\partial z} T^{*}(p, z)\right|_{z=\infty} & =0,\left.T^{*}(p, z)\right|_{z=0}=T_{i n}^{*}(p) .
\end{aligned}
$$

Then eq. (A.8)-(A.9) are:

$$
\begin{aligned}
& \frac{d^{2} c^{*}}{d z^{2}}-u_{1} \frac{d c^{*}}{d z}-q^{2} c^{*}=-\mathrm{F}^{*} \\
& \frac{d^{2}}{d z^{2}} T^{*}-u_{2} \frac{d}{d z} T^{*}-q_{2}^{2}(p) T^{*}=-\mathrm{F}_{2}^{*}(p),
\end{aligned}
$$

where $\quad u_{1}=\frac{u}{D_{\text {inter }}}, \quad q_{1}^{2}(p)=\frac{p(p+\beta(K+1))}{D_{\text {inter }}(p+\beta K)}, \quad \mathrm{F}^{*}=\frac{c_{0}}{D_{\text {inter }}}$, $u_{2}=\frac{u h_{g}}{\Lambda}, \quad q_{2}^{2}(p)=\frac{H p+\mathrm{X}^{2}}{\Lambda}, \quad \mathrm{F}_{2}^{*}(p)=\frac{1}{\Lambda}\left(H T_{0}-Q_{a d s} \beta \frac{p}{p+\beta K} c^{*}(p, z)\right)$

The solution of eq. (A.13) with conditions (A.10), (A.11) is [11, 14, 23]:

$$
c^{*}(p, z)=c_{\text {in }} \frac{1}{p} e^{\left(\frac{u_{1}}{2}-\omega(p)\right) z}+\frac{c_{0}}{D_{\text {inter }}} \int_{0}^{\infty} \mathrm{E}^{*}(p, z, \xi) d \xi,
$$

where $\omega_{1}(p)=\left(\frac{1}{4} u_{1}^{2}+q_{1}^{2}(p)\right)^{1 / 2}, \operatorname{Re} \omega_{1}>0, \mathrm{E}^{*}(p, z, \xi)$ - Cauchy function $[11,15]$ 


$$
\mathrm{E}^{*}(p, z, \xi)=\frac{1}{2 \omega_{1}(p)} e^{\frac{u_{1}}{2}(z-\xi)}\left(e^{-|z-\xi| \omega_{1}(p)}-e^{-(z+\xi) \omega_{1}(p)}\right)
$$

After integration, A.15 becomes:

$$
c^{*}(p, z)=\frac{c_{\text {in }}}{p} e^{\frac{u_{1}}{2} z} e^{-\omega_{1}(p) z}+c_{0} \frac{1}{K+1}\left[\frac{K}{p}+\frac{1}{p+\beta(K+1)}\right]\left(1-e^{\frac{u_{1} z}{2}} e^{-\omega_{1}(p) z}\right)
$$

Calculating the Laplace originals in eq. (A.17), we obtain:

$$
\begin{aligned}
& c(t, z)=c_{0} \frac{K}{K+1} L^{-1}\left[\frac{1}{p}\right]+\frac{c_{0}}{K+1} L^{-1}\left[\frac{1}{p+\beta(K+1)}\right]+\left(c_{i n}-c_{0}\right) e^{\frac{u_{1}}{2} z} L^{-1}\left[\frac{e^{-\omega_{1}(p) z}}{p}\right]+ \\
& +c_{0} \beta L^{-1}\left[\frac{1}{p+\beta(K+1)}\right] * L^{-1}\left[\frac{e^{-\omega_{1}(p) z}}{p}\right] e^{\frac{u_{1}}{2} z},
\end{aligned}
$$

where the Laplace original $L^{-1}\left[\frac{e^{-\omega_{1}(p) z}}{p}\right]$ after the calculation of the Bromwich integral is [13, 15]:

$\mathrm{W}_{c}(t, z)=L^{-1}\left[\frac{e^{-\omega_{1}(p) z}}{p}\right]=\frac{1}{2 \pi} \int_{i}^{\sigma_{0}-i \infty} \frac{e^{-\omega_{1}(p) z}}{p} e^{p t} d p=\frac{1}{\pi} \int_{0}^{\infty} e^{-\varphi_{1}(v) z} \frac{\sin \left(v t-z \varphi_{2}(v)^{2}\right)}{v} d v+e^{-\frac{u}{2 D_{\text {inter }}} z}$

where $\varphi_{1,2}(v)=\left[\frac{\left(\Gamma_{1}^{2}(v)+v^{2} \Gamma_{2}^{2}(v)\right)^{1 / 2} \pm \Gamma_{1}^{2}(v)}{2}\right]^{1 / 2}$,

$$
\Gamma_{1}(v)=\frac{u^{2}}{4 D_{\text {inter }}^{2}}+\frac{v^{2} \beta}{D_{\text {inter }}^{2}\left(v^{2}+\beta^{2} K^{2}\right)}, \quad \Gamma_{2}(v)=\frac{v^{3}+v \beta^{2}(K+1) K}{D_{\text {inter }}\left(v^{2}+\beta^{2} K^{2}\right)} .
$$

Substituting eq. (A.19) in eq. (A.18) we obtain the analytical solution of eq. (A.1)-(A.6) which describe the concentration of moisture in the gas phase and adsorbed on the solid:

$$
\begin{aligned}
& c(t, z)=\frac{K}{K+1} c_{0}+\frac{c_{0}}{K+1} e^{-\beta(K+1) t}+\left(c_{\text {in }}-c_{0}\right) e^{\frac{u_{1}}{2 D_{\text {inter }}} z} \mathrm{~W}_{c}(t, z)+ \\
& +\beta c_{0} e^{\frac{u}{2 D_{\text {inter }}} \int_{0}^{t} e^{-\beta(K+1)(t-s)} \mathrm{W}_{c}(s, z) d s} \\
& a(t, z)=\beta \int_{0}^{t} e^{-\beta K(t-\tau)} c(\tau, z) d \tau .
\end{aligned}
$$

Using the conditions $\left.c(t, z)\right|_{z=0}=c_{i n}(t)$ for the desorption phase, eq. (A.20) will be: 
$c(t, z)=\frac{K}{K+1} c_{0}+\frac{c_{0}}{K+1} e^{-\beta(K+1) t}+e^{\frac{u}{2 D_{\text {meter }}} z} \int_{0}^{t} \mathrm{~W}_{c}^{\text {in }}(t-\tau, z) c_{\text {in }}(\tau) d \tau-c_{0} e^{\frac{u}{2 D_{\text {miter }}} z} \mathrm{~W}_{c}^{0}(t, z)+$

$+\beta c_{0} e^{\frac{u}{2 D_{\text {iter }}}} \int_{0}^{t} e^{-\beta(K+1)(t-\tau)} \mathrm{W}_{c}^{0}(\tau, z) d \tau$,

where $\quad \mathrm{W}_{c}^{\text {in }}(t, z)=\frac{1}{\pi} \int_{0}^{\infty} e^{-\varphi_{1}(v) z} \cos \left(v t-\varphi_{2}(v)\right) d v$.

Similarly, the analytical solution of (A.1)-(A.6) which describes the temperature distribution in the adsorbent is $[13,15]$ :

$$
\begin{aligned}
& T(t, \mathrm{z})=T_{\text {in }}(0) \Phi_{T}^{0}(t, z)+\int_{0}^{t} \frac{d}{d \tau} T_{i n}(\tau) \Phi_{T}^{0}(t-\tau, z)+ \\
& +\frac{1}{\Lambda} \int_{0}^{t} \int_{0}^{\infty}\left[H T_{0} \mathrm{H}_{T}(t-\tau ; z, \xi)-Q_{a d s} \beta\left(\mathrm{H}_{T}(t-\tau ; z, \xi)-\beta K \int_{0}^{t-\tau} e^{-\beta K(t-\tau-s)} \mathrm{H}_{T}(\tau-s ; z, \xi) d s\right) c(p, \xi)\right] d \xi d \tau
\end{aligned}
$$

Here

$$
\begin{aligned}
& \mathrm{H}_{T}(\tau ; z, \xi)=e^{-\frac{u_{2}}{2}(z-\xi)}\left(\Phi_{T}(\tau,|z-\xi|)-\Phi_{T}(\tau, z+\xi)\right), \\
& \Phi_{T}(t, \mathrm{z}) \equiv L^{-1}\left[\frac{e^{-\omega_{2}(p) z}}{2 \omega_{2}(p)}\right]=\frac{1}{2 \pi} \int_{0}^{\infty} \frac{\phi_{1}(v) \cos \left(v t-\phi_{2}(v) \mathrm{z}\right)+\phi_{2}(v) \sin \left(v t-\phi_{2}(v) \mathrm{z}\right)}{\left(\Gamma_{T_{1}}^{2}(v)+v^{2} \Gamma_{T_{2}}^{2}(v)\right)^{1 / 2}} d v, \\
& \left.\Phi_{T}^{0}(t, z) \equiv L^{-1}\left[\frac{e^{-\omega_{2}(p) z}}{p}\right]=\frac{1}{\pi} \int_{0}^{\infty} e^{-\phi(v(v) z} \frac{\sin \left(v t-z \phi_{2}(v)^{2}\right)}{v} d v+e^{-\frac{u}{2 D_{\text {met }} z},}\right]^{1 / 2}, \Gamma_{T_{1}}(v)=\frac{u^{2}+4 \Lambda \mathrm{X}^{2}}{4 \Lambda^{2}}, \\
& \Gamma_{2}(v)=\frac{v^{3}+v \beta^{2}(K+1) K}{D_{\text {inter }}\left(v^{2}+\beta^{2} K^{2}\right)}, \phi_{1,2}(v)=\left[\frac{\left(\Gamma_{T_{1}}^{2}(v)+v^{2} \Gamma_{T_{2}}^{2}(v)\right)^{1 / 2} \pm \Gamma_{T_{1}}^{2}(v)}{2}\right]^{1 / 2} \\
& \Gamma_{T_{2}}(v)=\frac{H v}{\Lambda}, \omega_{2}(p)=\left(\frac{1}{4} u_{2}^{2}+q_{2}^{2}(p)\right)^{1 / 2}, \operatorname{Re} \omega_{2}>0 .
\end{aligned}
$$

